\title{
15 years of the International Journal of Intelligent Decision Technologies (IDT): Reflection from the Editors
}

\author{
Gloria Phillips-Wren, George A. Tsihrintzis, Lakhmi C. Jain and Junzo Watada
}

\section{Background}

The inspiration for IDT grew out of conversations between Professor/Dr. Gloria Phillips-Wren and Professor/Dr. Lakhmi Jain at the Knowledge Engineering Systems (KES) International annual conferences. The mission of KES is stated as "dissemination, transfer, sharing and brokerage of knowledge" to address knowledge-intensive subjects. As a large professional scientific community, KES sponsors a broad spectrum of publications and activities for research scientists, academics, engineers and practitioners. Research in intelligent agents and intelligent systems in the timeframe of 2004-2006 at KES conferences was focused on algorithms and technical specifications. During the same general time period, the technology was becoming mature enough to be implemented into real-world decision support systems (DSS) for previously intractable problems.

Thus, the idea emerged to create a special focus in KES that blended these two areas of technical aspects of intelligent systems and decision support through both a new journal and an annual conference. This ultimately resulted in a proposal for an interdisciplinary research journal that focused on supporting and advancing human decision making though the use of intelligent technologies. The journal was envisioned as bridging computer science with its development of artificial intelligence and intelligent agents, information systems with its development of decision support applications, and engineering with its development of systems.

The growth of the internet with its concomitant availability of data exploded the amount and types of information that must be considered by a decision maker.
Decisions must often be made in real-time under uncertain, stressful conditions that may change rapidly. Synergies between intelligent and information technologies can, for example, deliver artificial intelligence to enhance human judgment, perceive anomalies in data, enable collaboration, speed processing of new information, assist in risk assessment, identify and retrieve needed knowledge, suggest alternatives to the decision maker, and automate some decisional tasks.

Intelligent Decision Technologies (IDT): An International Journal is dedicated to advancing knowledge in the theory and application of intelligent technologies and systems that support decision making. The field of intelligent decision support has continued to expand rapidly and reach real systems due, in part, to advances in enabling technologies. Advances and efficiencies in Artificial Intelligence (AI), internet speeds, real-time data acquisition such as the Internet of Things (IoT), distributed data storage, data processing via cluster computing and virtualization, and network-centric environments such as cloud technologies can deliver intelligent systems at scale in real-time. Since many applications involve some type of decision, IDT provides a forum for original research that has the potential to improve decision making using intelligent technologies.

$I D T$ joined the flagship KES Journal as an official journal of KES a couple of years after its successful launch. IDT is also an annual conference series under the KES umbrella of Smart Digital Futures.

\section{Advisory Board, Authors, Reviewers, Special Issue Editors}

We would like to express our sincere appreciation to the Advisory Board, authors, reviewers and special 
issue editors for their outstanding contributions to IDT. Although there are too many people to mention individually, the community of researchers and practitioners affiliated with IDT continues to grow and to strengthen the research impact. Among other indices, IDT has been recognized by the Web of Science as an Emerging Sources Citation Index.

\section{Indexing}

$I D T$ is indexed in:

ACM Digital Library

Cabell's Guide or Directory

Compendex

DBLP Bibliography Server

EBSCO databases

Google Scholar

Inspec IET

Microsoft Academic Search

Scopus

Ulrich's Periodicals Directory

Web of Science: Emerging Sources Citation Index

\section{Editors}

2007 Founded by Gloria Phillips-Wren and Lakhmi C. Jain

Honorary editor: Robert J. Howlett, Executive Chair of KES

2010 Gloria Phillips-Wren, Lakhmi C. Jain, Junzo Watada

2016 CP Lim (managing editor), Gloria PhillipsWren, Lakhmi C. Jain, Junzo Watada

2018 George A. Tsihrintzis (managing editor), Gloria Phillips-Wren (special issue editor), Lakhmi C. Jain, Junzo Watada

\section{Bios of the Editors}

Gloria Phillips-Wren, PhD, MS, MBA, MEd, BA(summa cum laude) is Professor and past Chair of the Department of Information Systems, Law and Operations Management at Loyola University Maryland, USA. She is founder and co-editor-in-chief of Intelligent Decision Technologies (IDT) and Associate Editor of the Journal of Decision Systems (JDS). She is pastchair of the Special Interest Group on Decision Support and Analytics (SIGDSA) under the Association of Information Systems (AIS), Secretary of IFIP WG8.3
Decision Support (DS), and leader of a focus group for Knowledge Engineering Systems (KES) International in intelligent decision technologies. Her research interests and publications are in decision making and support, data analytics, business intelligence, healthcare IT, and strategic uses of technologies such as social media. She has published over 40 scholarly journal articles and 13 books (including co-edited), along with numerous book chapters and conference proceedings.

Contact Information: Sellinger School of Business and Management, Department of Information Systems, Law and Operations Management, Loyola University Maryland, 4501 N. Charles Street, Baltimore, MD, USA, email: gwren@loyola.edu

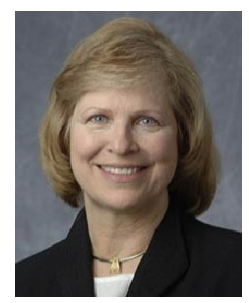

Lakhmi C. Jain, PhD, ME, BE(Hons), Fellow (Engineers Australia) is with the University of Technology Sydney, Australia, and Liverpool Hope University, UK. Professor Jain founded the KES International for providing a professional community the opportunities for publications, knowledge exchange, cooperation and teaming. Involving around 5,000 researchers drawn from universities and companies world-wide, KES facilitates international cooperation and generates synergy in teaching and research. KES regularly provides networking opportunities for the professional community through one of the largest conferences of its kind in the area of knowledge engineering systems (www.kesinternational.org). His interests focus on artificial intelligence paradigms and their applications in complex systems, security, e-education, e-healthcare and unmanned air vehicles.

Contact information: jainlakhmi@gmail.com

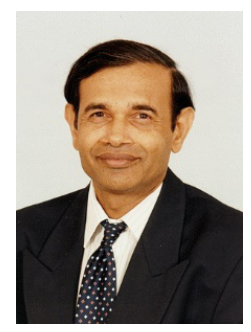

Junzo Watada, $\mathrm{PhD}$, Msci, Bsci is an IEEE Life Senior Member, a Life Fellow of the Japan Soci- 
ety for Fuzzy Theory and Intelligent Informatics, Japan, and a life fellow of the Bio-Medical Fuzzy System Association, Japan. He has been involved in KES, and especially IDT, for about 30 years. He is a gold member of KES and has received several awards by KES in the past. He also received the Henri Coanda Medal Award from Inventico, Romania, in 2002, and the GH Asachi Medal from the Universitatea Tehnica GH Asachi, IASI, Romania, in 2006. His research interests include big data analytics, soft computing, image processing systems to track human behaviors and understand pictures and videos, knowledge engineering, management engineering, and finance engineering. http://www.f.waseda.jp/waseda/; http://www.wcicme.com/watada/

Contact information: junzo.watada@gmail.com

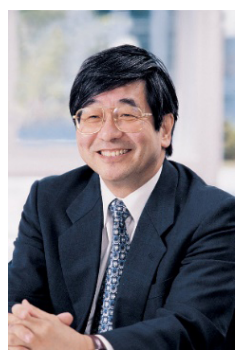

Chee Peng Lim received his Ph.D. degree from Department of Automatic Control and Systems Engineering, the University of Sheffield, UK, in 1997. He has published over 450 technical papers in journals, conference proceedings, and books, edited four books and 15 special issues in journals. Recipient of seven best paper awards in international conferences, his research focuses on the design and development of computational intelligence-based systems for pattern classification, decision support, and optimisation with application to medical prognosis and diagnosis, fault detection and classification, as well as manufacturing process optimisation. He was Co-Editor-in-Chief of Intelligent Decision Technologies.

Contact information: Institute of Intelligent Systems Research and Innovation Deakin University, Australia, email: chee.lim@deakin.edu.au

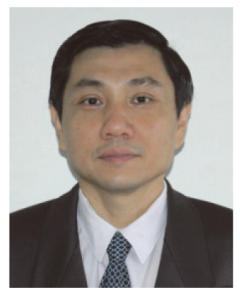

George A. Tsihrintzis, $\mathrm{PhD}, \mathrm{MSc}, \mathrm{BE}(\mathrm{Hons})$ is Professor in the Department of Informatics in the University of Piraeus, Greece, and served as its Head from Sept. 2016 through Aug. 2020. He received the fiveyear Diploma of Electrical Engineer from the National Technical University of Athens, Greece (with honours) and the M.Sc. and Ph.D. degrees in Electrical Engineering from Northeastern University, Boston, Massachusetts, USA. He is co-founder and co-editor of the Learning and Analytics in Intelligent Systems (LAIS) series (published by Springer) and the editor-in-chief of the International Journal of Computational Intelligence Studies (IJCISTUDIES) (published by Inderscience). His current research interests include Pattern Recognition, Machine Learning and Decision Theory and their applications in Artificial Intelligence-enhanced Software, Multimedia Interactive Services, User Modeling, Knowledge-based Software Systems, HumanComputer Interaction and Information Retrieval. He has authored or co-authored over 350 research publications in these areas, which include 5 monographs and 25 edited volumes.

Contact information: Department of Informatics, University of Piraeus, Piraeus 185 34, Greece, email: gatsihrintzis@gmail.com,geoatsi@unipi.gr

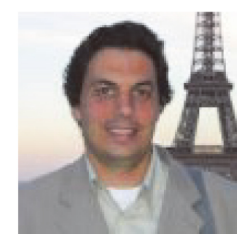

\section{Invitation to Contribute Original Research}

A refereed international scholarly journal, Intelligent Decision Technologies (IDT) welcomes original research contributions on the fundamental concepts and applications of intelligent systems that support decision making. The focus is interdisciplinary in nature and includes research on all aspects of intelligent decision technologies, from fundamental development to the applied system. Manuscripts are published on such diverse areas as artificial intelligence, fuzzy techniques, genetic algorithms, intelligent agents, multi-agent systems, cognitive science, mathematical modeling, neural systems/neural networks, computer-supported cooperative work, big data technologies, geographic information systems, knowledge management systems, user interface management systems, informatics, knowledge representation, applications of intelligent systems, and others.

ISSN 1872-4981 (P)

ISSN 1875-8843 (E) 